\title{
9-Borobicyclo[3.3.1]nonane-Catalyzed Hydroboration of Terminal Aromatic Alkynes with Pinacolborane
}

\author{
Garett L. Ruesch, Sydney L. Rowley, Marcus C. Mifflin, \& Nathan S. Werner* \\ Department of Physical Science, Southern Utah University, Cedar City, UT \\ https:/ / doi.org/10.33697/ ajur.2020.011 \\ Students: garett.ruesch@gmail.com,sydney.rowley.17@gmail.com,mifflinma@gmail.com \\ Mentor:nathanwerner@suu.edu*
}

\begin{abstract}
Organoboron compounds are extensively used in organic synthesis. The alkenylboronic acid pinacol esters formed from the hydroboration reaction of alkynes with pinacolborane are stable, easy to handle, and useful in many synthetic transformations. However, pinacolborane lacks the reactivity necessary to undergo facile hydroboration reaction with terminal aromatic alkynes. 9Borobicyclo[3.3.1] nonane (9-BBN) can be used to catalyze the hydroboration reaction of phenylacetylene with pinacolborane. The hydroboration reaction parameters and product purification conditions were evaluated to maximize the yield of (E)-2phenylethenylboronic acid pinacol ester. It was found that the optimal reaction conditions for the 9-BBN-catalyzed hydroboration of phenylacetylene with pinacolborane were: phenylacetylene (1.0 equiv), pinacolborane (1.2 equiv), 9-BBN (20 mol\%), and THF $[0.2]$ at $65^{\circ} \mathrm{C}$. The compatibility of these reaction conditions with $p$-substituted terminal aromatic alkynes bearing electronically diverse groups was studied. Moderate to good yield (49-76\%) of the hydroboration products were isolated after purification by liquid-liquid extraction and flash chromatography.
\end{abstract}

\section{KEYWORDS}

Organic Synthesis; Catalysis; Methods Development; Hydroboration; Reaction Optimization; Alkenylboronic Ester; Alkyne; Pinacolborane; 9-Borobicyclo[3.3.1] nonane

\section{INTRODUCTION}

Boron containing organic compounds are useful reagents in the synthesis of important carbon-containing medicines, materials, and fine chemicals. The utility of these reagents is evident from the variety of bonds, and therefore functional groups, which can be substituted for the $\mathrm{C}-\mathrm{B}$ bond. For example, the hydroboration-oxidation reaction of an alkene ultimately transforms the $\mathrm{C}-\mathrm{B}$ bond into a $\mathrm{C}-\mathrm{O}$ bond. ${ }^{1}$ The $\mathrm{C}-\mathrm{B}$ bond can be substituted for a $\mathrm{C}-\mathrm{H}$ bond by protonolysis, ${ }^{2}$ or a $\mathrm{C}-\mathrm{X}$ bond by halogenation. ${ }^{3}$ In

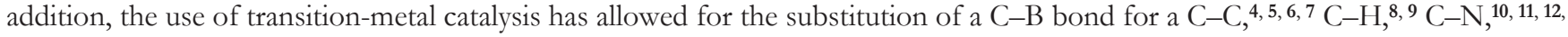
${ }^{13,14} \mathrm{C}-\mathrm{O},{ }^{15,16,17} \mathrm{C}-\mathrm{P},{ }^{18,19}$ or C-S bond, ${ }^{20,21}$ and include asymmetric variants. ${ }^{22}$

The hydroboration reaction of unsaturated organic substrates with hydroboron reagents is a straight-forward method to prepare alkyl- and alkenylboron compounds. An early example of the hydroboration reaction of alkenes was reported by Brown in 1956.1, 23 In 1966, Woods and Strong reported that alkynes undergo sluggish hydroboration with 4,4,6-trimethyl-1,3,2-dioxaborinane in a sealed tube of superheated ether to provide the alkenylboron products in low yield. ${ }^{24}$ Chemists have sought to catalyze the hydroboration reaction with transition metals, ${ }^{25,26,27,28,29,30,31,32}$ and alkaline earth metals, ${ }^{33,}, 34$ aluminum, ${ }^{35,35,36,37}$ base, ${ }^{38,39} \mathrm{~N}, \mathrm{~N}$ dimethylacetamide, ${ }^{40}$ and benzoic acid derivatives. ${ }^{41,42}$ Boron reagents are also known to catalyze the hydroboration reaction. ${ }^{43}$, 44 , 45, 46, 47, 48 In 1990, Periasamy et al. reported that a $\mathrm{BH}_{3} \cdot N, N$-diethylaniline complex could catalyze the hydroboration of terminal alkynes with catecholborane. ${ }^{43}$ Hoshi et al. later reported that dicyclohexylborane could catalyze the hydroboration reaction of terminal alkynes with pinacolborane in good to excellent yield. ${ }^{4}{ }^{4}$

Our interest in the hydroboration reaction originated with the need to synthesize (E)-2-phenylethenyl boronic acid pinacol ester (E)-3a (Scheme 1) for use as an organometallic donor in Suzuki-Miyaura cross-coupling reactions. ${ }^{7}$ The reagent (E)-3a could be synthesized by hydroboration reaction with catecholborane followed by diol exchange with pinacol. ${ }^{51}$ However, the use of catecholborane is not ideal. For example, catechol is sensitive to oxidation, and the catecholborane product can decompose upon exposure to air or moisture. ${ }^{52}$ To avoid the use of catechol, a direct hydroboration reaction of $1 \mathrm{a}$ with pinacolborane 4 was sought. The reagent 4 is commercially available and more stable than catecholborane. Although the increased stability of 4 also lessens its reactivity in the hydroboration reaction. For example, the hydroboration reaction of $1 \mathrm{a}$ (1 equiv) with 4 (1.2 equiv) is sluggish in refluxing THF $\left(65^{\circ} \mathrm{C}\right)$, and only trace amounts of product (E)-3a was observed after $7 \mathrm{~h}$ vide infra. It was found that 9 borobicyclo[3.3.1]nonane (9-BBN) could be used to catalyze the hydroboration reaction of $1 \mathrm{a}$ with $4 .{ }^{7}$ The initially evaluated 
reaction conditions were determined to be satisfactory at the time and were not optimized. The reaction parameters and purification conditions have since been studied in detail and are described here.

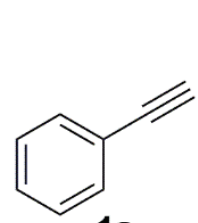

1a

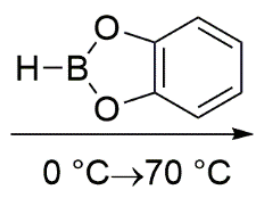

$0{ }^{\circ} \mathrm{C} \rightarrow 70^{\circ} \mathrm{C}$<smiles>C(=C/c1ccccc1)\B1Oc2ccccc2O1</smiles>

$(E)-2$

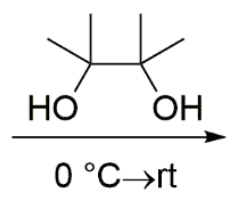

$0^{\circ} \mathrm{C} \rightarrow \mathrm{rt}$<smiles>CC1(C)OB(/C=C/c2ccccc2)OC1(C)C</smiles>

$(E)-3 a$

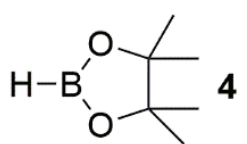

Scheme 1.

\section{RESULTS AND DISCUSSION}

This study began with the use of the previously published reaction conditions: 1a (1.0 equiv), 4 (1.0 equiv), 9-BBN (10 mol\%) in refluxing $0.2 \mathrm{M}$ THF solution (Table 1). ${ }^{7}$ On a $1 \mathrm{mmol}$ scale, the hydroboration product (E)-3a was isolated from this reaction as a slightly yellow oil in $62 \%$ yield after purification by liquid-liquid extraction and flash chromatography (entry 1). The effect of reagent stoichiometry on the yield of $(E)-3 \mathbf{a}$ was then evaluated. Increasing the amount of $\mathbf{4}$ to 1.2 equiv increased the yield to $73 \%$ (entry 2). Further increasing the amount of 4 to 1.4 equivalents decreased the yield of (E)-3a (entry 3 ). The use of excess $1 \mathbf{a}$ (1.2 equiv) and 4 (1.0 equiv) as the limiting reactant provided a 69\% yield of (E)-3a (entry 4). A range from $0-30 \mathrm{~mol} \%$ of 9-BBN was tested, and $20 \mathrm{~mol} \%$ was found to provide the highest yield of (E)-3a (entries 12-15).

The reaction parameters of concentration, temperature, and a $\mathrm{NaOH}$ additive were also evaluated. It was found that concentrations between $0.2 \mathrm{M}$ and neat ${ }^{49}$ caused little change in the amount of (E)-3a that was isolated (entries 5-7). However, a more dilute reaction $(0.04 \mathrm{M}$ ) produced significantly less (E)-3a (entry 5). Toluene and 1,4-dioxane were evaluated as solvent and were found to provide a lower yield than when THF was used as the reaction solvent (entries 10 and 11). A decreased reaction temperature resulted in a decreased yield of (E)-3a (entry 8). An increased reaction temperature resulted in an increased yield of (E)-3a when 1,4-dioxane was used as solvent (entries 9 and 10). However, the yield of (E)-3 was higher when the reaction was run in THF at $65{ }^{\circ} \mathrm{C}$ than when the reaction was run in 1,4-dioxane at $85^{\circ} \mathrm{C}$ (compare entries 2 and 10). The addition of $\mathrm{NaOH}(5$ mol\%) resulted in a slightly decreased yield of (E) $-3 a($ entry 16$) .{ }^{38}$

Various stationary phases were evaluated for the purification of (E)-3a by flash chromatography. The use of a boric acid capped silica provided a negligible difference in yield and purity as determined by ${ }^{1} \mathrm{H}$ NMR (entry 17$) .{ }^{50}$ The crude product (E)-3a was entirely lost when the flash chromatography was conducted with a dry, neutral alumina stationary phase (entry 18). 
Table 1. Evaluation of the reaction parameters of the 9-BBN-catalyzed hydroboration reaction of $1 \mathrm{a}$ with 4.<smiles>C#Cc1ccccc1</smiles>

1a, equiv.<smiles>CC1(C)OBBOC1(C)C</smiles>

4, equiv.

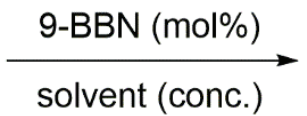

temp. $\left({ }^{\circ} \mathrm{C}\right)$<smiles>CC1(C)OB(/C=C/c2ccccc2)OC1(C)C</smiles>

$(E)-\mathbf{3 a}$

\begin{tabular}{|c|c|c|c|c|c|}
\hline entry & HB(pin), mmol & 9-BBN, $\mathrm{mol} \%$ & solvent, conc. & temp., ${ }^{\circ} \mathrm{C}$ & $\mathrm{C}$ yield, $\mathrm{a} \%$ \\
\hline 1 & 1 & 10 & THF, 0.2 & 65 & 62 \\
\hline 2 & 1.2 & 10 & THF, 0.2 & 65 & 73 \\
\hline 3 & 1.4 & 10 & THF, 0.2 & 65 & 67 \\
\hline $4^{b}$ & 1 & 10 & THF, 0.2 & 65 & 69 \\
\hline 5 & 1.2 & 10 & THF, 0.04 & 65 & 53 \\
\hline 6 & 1.2 & 10 & THF, 1.0 & 65 & 71 \\
\hline 7 & 1.2 & 10 & neat $^{c}$ & 65 & 69 \\
\hline 8 & 1.2 & 10 & THF, 0.2 & 45 & 54 \\
\hline 9 & 1.2 & 10 & dioxane, 0.2 & 65 & 48 \\
\hline 10 & 1.2 & 10 & dioxane, 0.2 & 85 & 59 \\
\hline 11 & 1.2 & 10 & toluene, 0.2 & 65 & 54 \\
\hline 12 & 1.2 & - & THF, 0.2 & 65 & $0^{\mathrm{d}}$ \\
\hline 13 & 1.2 & 5 & THF, 0.2 & 65 & 46 \\
\hline 14 & 1.2 & 20 & THF, 0.2 & 65 & 76 \\
\hline 15 & 1.2 & 30 & THF, 0.2 & 65 & 71 \\
\hline $16^{\mathrm{e}}$ & 1.2 & 10 & THF, 0.2 & 65 & 66 \\
\hline $17^{\mathrm{f}}$ & 1.2 & 10 & THF, 0.2 & 65 & 63 \\
\hline $18^{\mathrm{g}}$ & 1.2 & 10 & THF, 0.2 & 65 & 0 \\
\hline
\end{tabular}

aYield of isolated, purified product.

b1.2 equiv of phenylacetylene was used.

c9-BBN was used as a $0.5 \mathrm{M}$ solution in THF. The final reaction concentration was $2.5 \mathrm{M}$.

dNo product was observed after $7 \mathrm{~h}$.

${ }^{e} \mathrm{NaOH}(5 \mathrm{~mol} \%)$ was added as a co-catalyst.

${ }^{\mathrm{f} B o r a t e d ~ s i l i c a ~ w a s ~ u s e d ~ a s ~ t h e ~ c h r o m a t o g r a p h y ~ s t a t i o n a r y ~ p h a s e . ~}$

sDry, neutral alumina was used as the chromatography stationary phase

The optimized reaction conditions of 1 (1.0 equiv), 4 (1.2 equiv), 9-BBN (20 mol\%), and THF [0.2] at $65^{\circ} \mathrm{C}$ were then used to evaluate the scope of compatible $p$-substituted terminal aromatic alkynes $1 \mathrm{a}-\mathrm{e}$. The electronically neutral parent alkyne $1 \mathrm{a}$ provided the highest yield $(76 \%)$ and was found to react the fastest under the optimized reaction conditions (entry 1). Substrates with electron-donating methyl and methoxy groups provided a good yield of the desired products $(E)-3 \mathbf{b}$ and $(E)-3 \mathbf{c}($ entries 2 and 3). A substrate bearing an electron-withdrawing methyl ester group provided the lowest yield of the substrates evaluated (entry 4). The good yield of the bifunctional, 4-bromo derivative (E)-3e is especially interesting because it could be used as an organic electrophile or organometallic donor in a Suzuki-Miyaura cross-coupling reaction. Complete control of the alkene geometry of (E)-3a-e was observed by ${ }^{1} \mathrm{H}$ NMR spectroscopy in all of the cases studied. 
Table 2. Evaluation of the optimized reaction conditions with 1 a and electronically diverse $p$-substituted terminal aromatic alkynes 1b-1e.

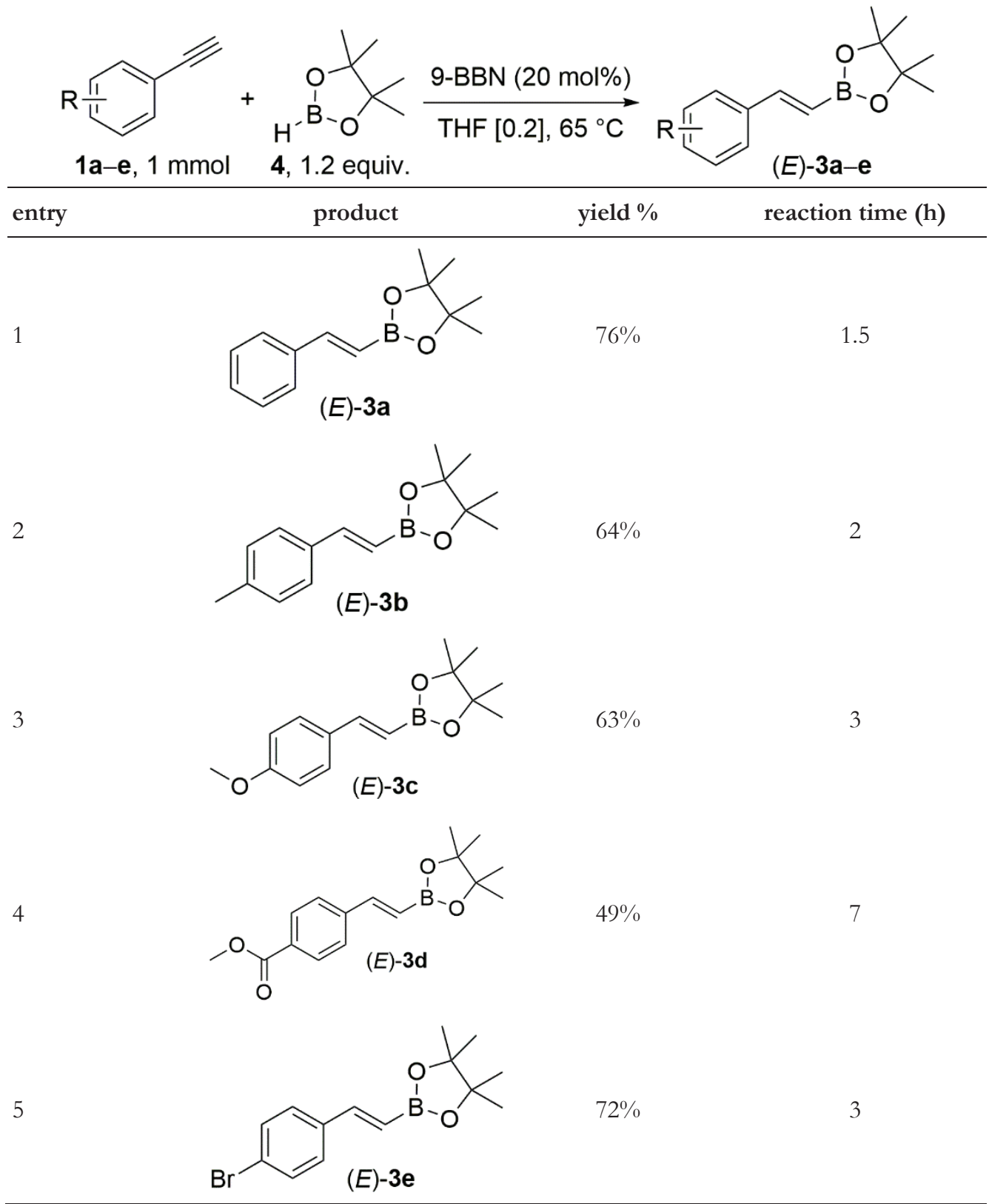

\section{METHODS AND PROCEDURES}

General Procedure: An oven-dried, round-bottom flask equipped with a magnetic stir-bar was fitted with an oven-dried Liebig condenser and sealed with high-vacuum grease. The reflux apparatus was capped with a septum and purged with a balloon of argon that was introduced and evacuated through a needle for 15 minutes. The following were added sequentially by syringe under a balloon of argon: the terminal aromatic alkyne, pinacolborane, 9-BBN ([0.5] in THF), and finally a small portion of solvent to wash all of the reagents into the round-bottomed flask. The reaction solution was refluxed in a preheated oil bath at 65 ${ }^{\circ} \mathrm{C}$. Reaction aliquots were analyzed by thin-layer chromatography (TLC) to monitor the disappearance of the alkyne starting material. When the reaction was determined to be complete, it was cooled to room temperature, extracted with ethyl acetate, washed with water, brine, dried with sodium sulfate, filtered and concentrated by rotary evaporation $\left(50{ }^{\circ} \mathrm{C}, 2\right.$ torr $)$. The crude product was purified by flash chromatography on silica. The amount of silica used in the chromatography was approximately 65 times the mass of the concentrated crude product. The eluent began with 98.5:1.5, hexane/ethyl acetate and increased to 95:5, 
hexane/ethyl acetate until the product was completely eluted. The product was concentrated in vacuo (2 torr) to afford the desired product.

Procedure for the Synthesis of 4,4,5,5-Tetramethyl-2-[(1E)-2-phenylethenyl]-1,3,2-dioxaborolane ((E)-3a)<smiles>C#Cc1ccccc1</smiles>

$1 \mathrm{a}, 1 \mathrm{mmol}$

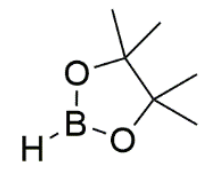

4, 1.2 equiv.

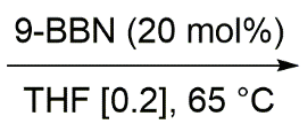

THF [0.2], $65^{\circ} \mathrm{C}$

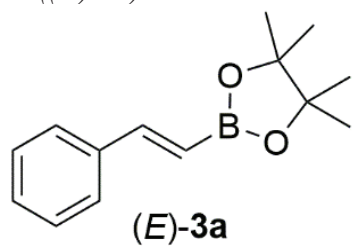

Following the General Procedure, phenylacetylene (110 $\mu \mathrm{L}, 1.0 \mathrm{mmol}, 1.0$ equiv), pinacolborane (174 $\mu \mathrm{L}, 1.2 \mathrm{mmol}, 1.2 \mathrm{equiv})$, 9BBN $\left(0.400 \mathrm{~mL},[0.5], 0.2 \mathrm{mmol}, 0.2\right.$ equiv), and THF $(5 \mathrm{~mL})$ were combined and heated to $65^{\circ} \mathrm{C}$ for $1.5 \mathrm{~h}$. Purification by aqueous workup and flash chromatography afforded $175 \mathrm{mg}(76 \%)$ of $(E)-3 a$ as a slightly yellow oil. ${ }^{38}$

Data for 4,4,5,5-Tetramethyl-2-[(1E)-2-phenylethenyl]-1,3,2-dioxaborolane ((E)-3a):

${ }^{1} \mathrm{H}$ NMR: $\quad\left(400 \mathrm{MHz}, \mathrm{CDCl}_{3}\right)$

7.48-7.45 (m, $2 \mathrm{H}), 7.40$ (d, $J=18.5,1 \mathrm{H}), 7.33-7.23(\mathrm{~m}, 3 \mathrm{H}) 6.17(\mathrm{~d}, J=18.5,1 \mathrm{H}), 1.29$ (s, $12 \mathrm{H})$.

${ }^{13} \mathrm{C} \mathrm{NMR}: \quad\left(101 \mathrm{MHz}, \mathrm{CDCl}_{3}\right)$

149.5, 137.5, 128.9, 128.6, 127.1, 83.4, 24.9.

IR: (neat)

3080 (w), 3054 (w), 3018 (w), 2978 (w), 2928 (w), 1623 (m), 1577 (w), 1495 (w), 1450 (m), 1391 (m), 1371 (m), 1346 (s), 1322 (s), 1271 (m), 1237 (m), 1210 (m), 1142 (s), 1109 (w), 997 (m), 969 (m), 899 (m), 851 (m), 748 (m), $692(\mathrm{~m}), 660(\mathrm{w}), 641(\mathrm{w})$.

MS: $\quad(\mathrm{EI}, 70 \mathrm{eV})$ 230 ([M] $\left.]^{+}, 49\right), 229$ (12), 215 (24), 157 (11), 145 (38), 144 (69), 143 (10), 131 (56), 130 (100), 129 (92), 118 (16), 114 (14), 105 (31), 104 (15), 103 (16), 85 (10), 78 (12), 77 (21).

TLC: $\quad R_{\mathrm{f}} 0.53$ (hexane/ethyl acetate, 95:5) [silica gel, aqueous $\mathrm{KMnO}_{4}$ ]

Procedure for the Synthesis of 4,4,5,5-Tetramethyl-2-[(1E)-2-(4-methylphenyl)ethenyl]-1,3,2-dioxaborolane ((E)-3b)

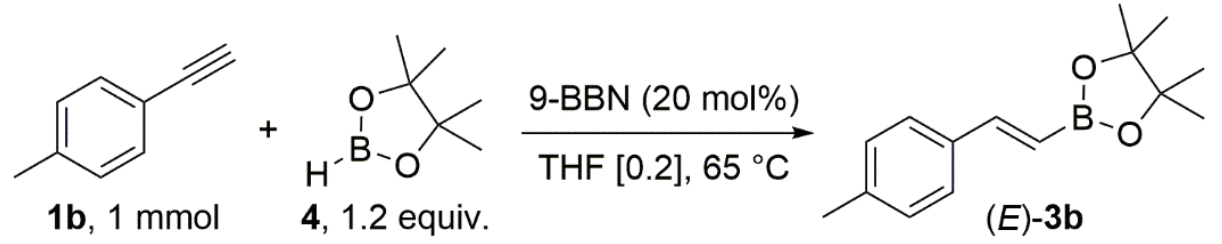

Following the General Procedure, 4-tolylacetylene (127 $\mu \mathrm{L}, 1.0 \mathrm{mmol}, 1.0$ equiv), pinacolborane (174 $\mu \mathrm{L}, 1.2 \mathrm{mmol}, 1.2 \mathrm{equiv})$, 9BBN $\left(0.400 \mathrm{~mL},[0.5], 0.2 \mathrm{mmol}, 0.2\right.$ equiv), and THF $(5 \mathrm{~mL})$ were combined and heated to $65^{\circ} \mathrm{C}$ for $2 \mathrm{~h}$. Purification by aqueous workup and flash chromatography afforded $157 \mathrm{mg}(64 \%)$ of $(E)-3 \mathbf{b}$ as a slightly yellow oil. ${ }^{37}$

Data for 4,4,5,5-Tetramethyl-2-[(1E)-2-(4-methylphenyl)ethenyl]-1,3,2-dioxaborolane ((E)-3b)

${ }^{1}$ H NMR: $\quad\left(400 \mathrm{MHz}^{\mathrm{H}} \mathrm{CDCl}_{3}\right)$

7.40-7.38 (m, $2 \mathrm{H}), 7.38(\mathrm{~d}, J=18.5,1 \mathrm{H}), 7.15-7.13(\mathrm{~m}, 2 \mathrm{H}), 6.11(\mathrm{~d}, J=18.5,1 \mathrm{H}), 2.34(\mathrm{~s}, 3 \mathrm{H}), 1.31(\mathrm{~s}, 12$ $\mathrm{H})$.

${ }^{13} \mathrm{C} \mathrm{NMR}: \quad\left(101 \mathrm{MHz}, \mathrm{CDCl}_{3}\right)$

149.6, 139.1, 134.9, 129.4, 127.2, 83.4, 25.0, 21.5.

IR: (neat)

2976 (w), 2926 (w), 1625 (m), 1569 (w), 1511 (w), 1479 (w), 1451 (w), 1411 (w), 1379 (m), 1370 (m), 1345 (m), 1320 (s), 1285 (w), 1264 (w), 1220 (w), 1204 (w), 1178 (w), 1165 (w), 1138 (s), 1109 (m), 1019 (s), 999 (m), 969 (m), 950 (w), 901 (w), 853 (w), 843 (m), 829 (w), 796 (s), 759 (w), 712 (w), 676 (w), 659 (w), 642 (w), 580 (w), $517(\mathrm{w}), 492(\mathrm{~m}), 453(\mathrm{w})$.

MS: $\quad(\mathrm{EI}, 70 \mathrm{eV})$

$245\left([\mathrm{M}+1]^{+}, 12\right), 244\left([\mathrm{M}]^{+}, 69\right), 243\left([\mathrm{M}-1]^{+}, 17\right), 229(21), 171(12), 159(40), 158(54), 145(38), 144(92), 143$ (100), 132 (19), 128 (47), 127 (13), 119 (17), 118 (12), 117 (43), 116 (29), 115 (36), 91 (18), 43 (15), 41 (17), 40 (11).

TLC: $\quad R_{\mathrm{f}} 0.42$ (hexane/ethyl acetate, 95:5) [silica gel, aqueous $\mathrm{KMnO}_{4}$ ] 
Procedure for synthesis of 2-[(1E)-2-(4-Methoxyphenyl)ethenyl]-4,4,5,5-tetramethyl-1,3,2-dioxaborolane ((E)-3c)

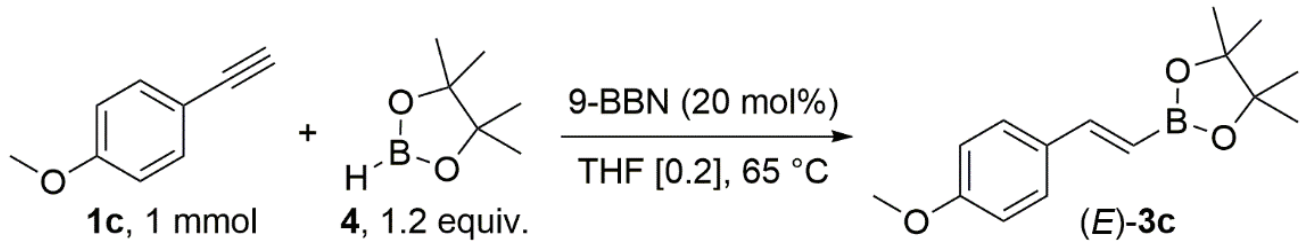

Following the General Procedure, 4-ethynylanisole (130 mg, $1.0 \mathrm{mmol}, 1.0$ equiv), pinacolborane (174 $\mu \mathrm{L}, 1.2 \mathrm{mmol}, 1.2 \mathrm{equiv})$, 9-BBN (0.400 mL, [0.5], $0.2 \mathrm{mmol}, 0.2$ equiv), and THF ( $5 \mathrm{~mL}$ ) were combined and heated to $65^{\circ} \mathrm{C}$ for 3 h. Purification by aqueous workup and flash chromatography afforded $132 \mathrm{mg}(51 \%)$ of $(E)-3 \mathrm{c}$ as a slightly yellow oil. ${ }^{46}$

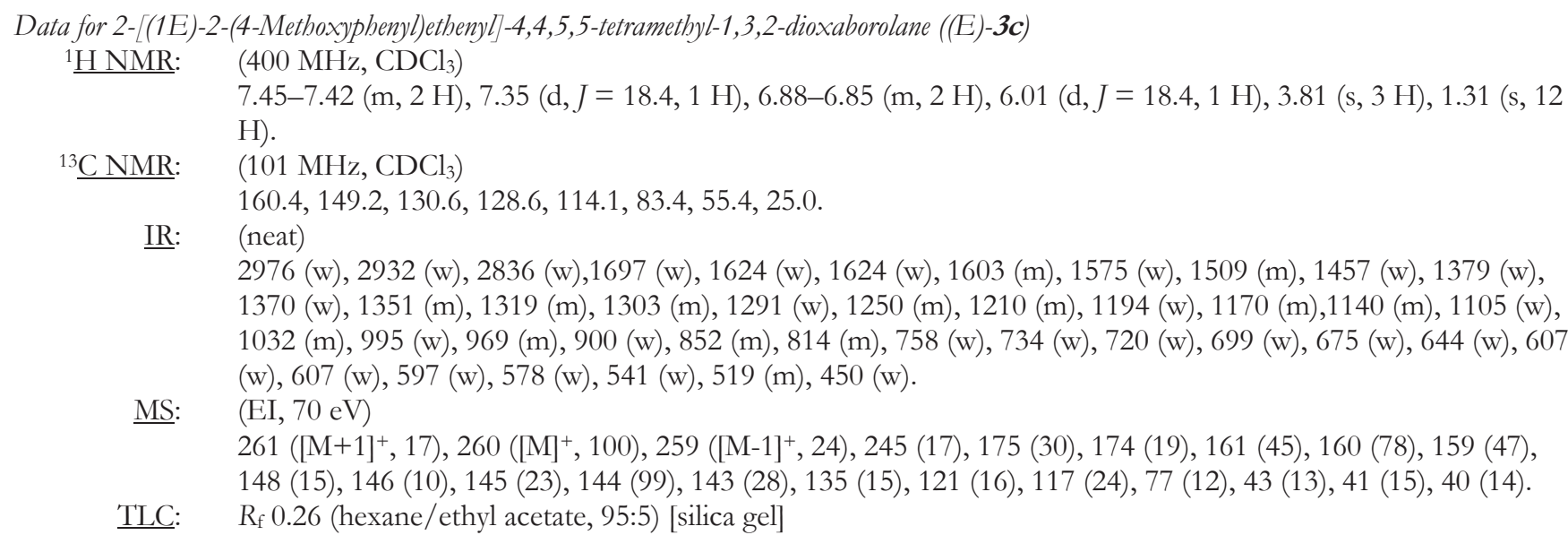

Procedure for the Synthesis of 4-[(1E)-2-(4,4,5,5-Tetramethyl-1,3,2-dioxaborolan-2-yl)ethenyl]benzoic acid methyl ester ((E)-3d)

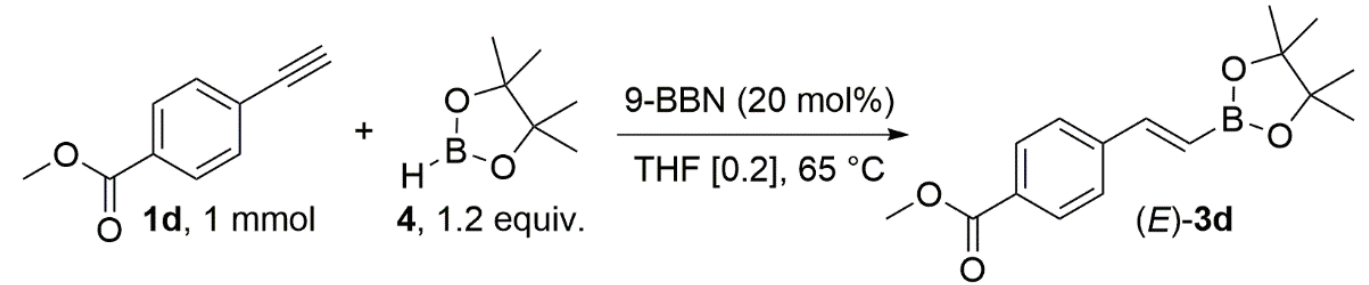

Following the General Procedure, methyl 4-ethynylbenzoate (160 mg, $1.0 \mathrm{mmol}, 1.0$ equiv), pinacolborane $(174 \mu \mathrm{L}, 1.2 \mathrm{mmol}, 1.2$ equiv), 9-BBN (0.400 mL, [0.5], $0.2 \mathrm{mmol}, 0.2$ equiv), and THF ( $5 \mathrm{~mL}$ ) were combined and heated to $65^{\circ} \mathrm{C}$ for $7 \mathrm{~h}$. Purification by aqueous workup and flash chromatography afforded $149 \mathrm{mg}(52 \%)$ of $(E)-3 \mathbf{d}$ as off-white crystals. ${ }^{46}$

Data for 4-[(1E)-2-(4,4,5,5-Tetramethyl-1,3,2-dioxaborolan-2-yl)ethenyl] benzoic acid methyl ester ((E)-3d)

${ }^{1} \mathrm{H}$ NMR: $\quad\left(400 \mathrm{MHz}, \mathrm{CDCl}_{3}\right)$ 8.00-7.98 (m, $2 \mathrm{H}), 7.53-7.51(\mathrm{~m}, 2 \mathrm{H}), 7.40(\mathrm{~d}, J=18.4,1 \mathrm{H}), 3.89$ (s, $3 \mathrm{H}), 1.30(\mathrm{~s}, 12 \mathrm{H})$.

${ }^{13} \mathrm{C}$ NMR: $\quad\left(101 \mathrm{MHz}, \mathrm{CDCl}_{3}\right)$

$166.8,148.2,141.8,130.2,130.0,127.0,83.6,52.2,24.9$.

IR: (neat) 2975 (w), 2950 (w), 2931 (w), 2848 (w), 1712 (s), 1672 (w), 1627 (m), 1605 (m), 1566 (w), 1487 (w), 1441 (m), 1413 (w), 1380 (w), 1368 (m), 1349 (s), 1319 (s), 1275 (s), 1214 (m), 1195 (m), 1173 (m), 1149 (m), 1111 (s), $1015(\mathrm{w}), 1002(\mathrm{~m}), 972(\mathrm{~m}), 902(\mathrm{w}), 872(\mathrm{~m}), 855(\mathrm{~m}), 844(\mathrm{~m}), 835(\mathrm{~m}), 804(\mathrm{w}), 758(\mathrm{~s}), 703(\mathrm{~m}), 690(\mathrm{~m})$, 667 (w), 652 (w), $638(\mathrm{~m}), 630(\mathrm{~m}), 579(\mathrm{w}), 518(\mathrm{w}), 508(\mathrm{~m}), 487(\mathrm{w}), 479(\mathrm{w}), 451(\mathrm{w})$.

MS: $\quad(\mathrm{EI}, 70 \mathrm{eV})$ $288\left([\mathrm{M}]^{+}, 49\right), 287\left([\mathrm{M}-1]^{+}, 15\right), 273(32), 257$ (19), 203 (29), 202 (57), 189 (20), 188 (30), 187 (53), 176 (18), 172 (13), 171 (15), 158 (11), 157 (100), 156 (32), 143 (45), 130 (11), 129 (39), 128 (17), 77 (29), 59 (15), 43 (20), 41 (21).

MP: $\quad 108-109^{\circ} \mathrm{C}$

TLC: $\quad \mathrm{R}_{\mathrm{f}} 0.18$ (hexane/ethyl acetate, 95:5) [silica gel, aqueous $\mathrm{KMnO}_{4}$ ] 
Procedure for the Synthesis of 2-[(1E)-2-(4-Bromophenyl)ethenyl]-4,4,5,5-tetramethyl-1,3,2-dioxaborolane ((E)-3e)

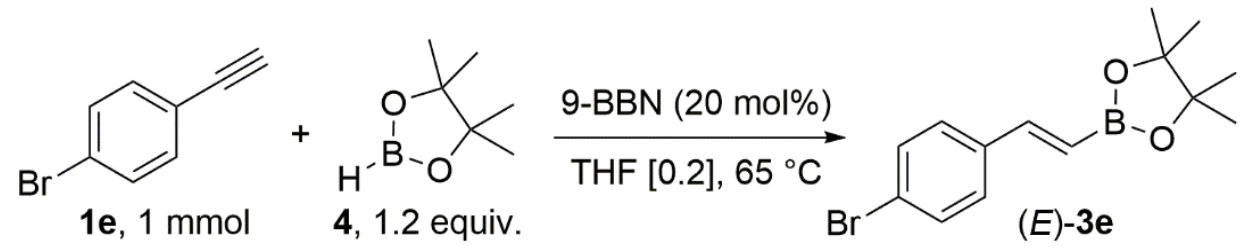

Following the General Procedure, 1-bromo-4-ethynylbenzene (309 mg, $1.0 \mathrm{mmol}, 1.0$ equiv), pinacolborane (174 $\mu \mathrm{L}, 1.2 \mathrm{mmol}$, 1.2 equiv), 9-BBN (0.400 mL, [0.5], $0.2 \mathrm{mmol}, 0.2$ equiv), and THF (5 mL) were combined and heated to $65^{\circ} \mathrm{C}$ for $3 \mathrm{~h}$.

Purification by aqueous workup and flash chromatography afforded $220 \mathrm{mg}(71 \%)$ of $(E)-3 \mathrm{e}$ as white crystals. ${ }^{37}$

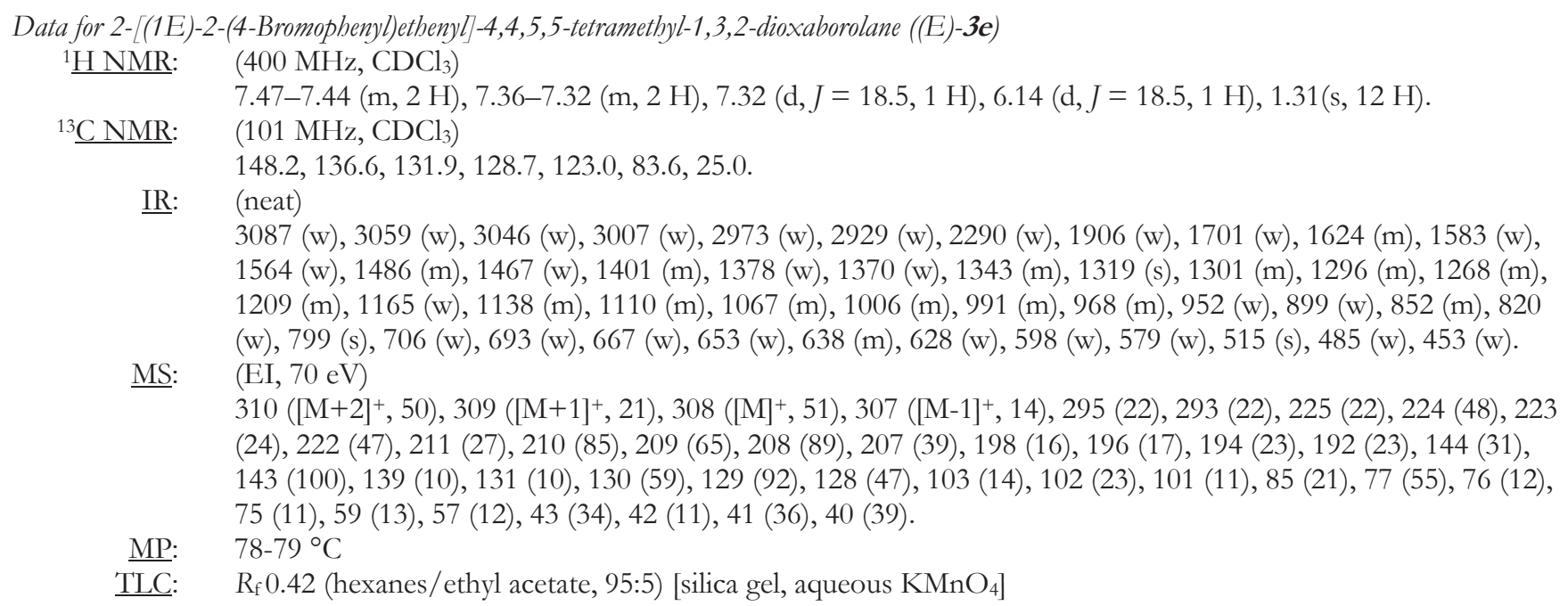

\section{CONCLUSION}

(E)-2-phenylethenyl boronic acid pinacol ester derivatives can be readily prepared by 9-BBN-catalyzed hydroboration reaction of terminal aromatic alkynes with pinacolborane. The use of $20 \mathrm{~mol} \%$ of $9-\mathrm{BBN}$ was found to provide the best yield of the hydroboration product. A variety of electronically diverse substrates provided moderate to good yields of the (E)-2-phenylethenyl boronic acid pinacol ester derivatives $(E)-3 a-e$. The bifunctional, 4-bromo derivative is especially interesting because it could be used as an organic electrophile or organometallic donor in a cross-coupling reaction. Complete control of the alkene geometry of the alkenylboronic ester product was observed in all of the cases studied. We intend to continue to explore the scope of this reaction and the synthetic utility of the boronic acid pinacol ester products.

\section{ACKNOWLEDGEMENTS}

We are grateful to Organic Syntheses Inc. for a Summer Research at an Undergraduate Institution Grant (N.S.W.), and Southern Utah University for a Faculty Project Fund Grant (N.S.W.), Walter Maxwell Gibson Research Fellowships (G.L.R. \& S.L.R.) and L. S. and Aline W. Skaggs Research Grant (S.L.R.) to generously support this work.

\section{REFERENCES}

1. Subba Rao, B. C., Brown, H. C. (1956) A new technique for the conversion of olefins into organoboranes and related alcohols, J Am Chem Soc 78, 5694-5695. https:// doi.org/10.1021/ja01602a063

2. Brown, H. C., Murray, K. (1959) Convenient non-catalytic conversion of olefinic derivatives into saturated compounds through hydroboration and protonolysis, J Am Chem Soc 81, 4108-4109. https://doi.org/10.1021/ja01524a073

3. Szyling, J., Franczyk, A., Pawluc, P., Marciniec, B., Walkowiak, J. (2017) A stereoselective synthesis of (E)-or (Z)- $\beta$-arylvinyl halides via a borylative coupling/halodeborylation protocol, Org Biomol Chem 15, 3207-3215. bttps:// doi.org/10.1039/C7OB00054E

4. Lennox, A. J., Lloyd-Jones, G. C. (2014) Selection of boron reagents for Suzuki-Miyaura coupling, Chem Soc Rev 43, 412-443. bttps:// doi.org/10.1039/C3CS60197H

5. Miyaura, N., Suzuki, A. (1995) Palladium-catalyzed cross-coupling reactions of organoboron compounds, Chem Rev 95 , 2457-2483. https://doi.org/10.1021/cr00039a007

6. Fagnou, K., Lautens, M. (2003) Rhodium-catalyzed carbon-carbon bond-forming reactions of organometallic compounds, Chem Rev 103, 169-196. https://doi.org/10.1021/cr020007u 
7. Rau, H. H., Werner, N. S. (2018) Stereocontrolled synthesis of (E)-stilbene derivatives by palladium-catalyzed Suzuki-Miyaura cross-coupling reaction, Bioorg Med Chem Lett 28, 2693-2696. https:/ / doi.org/10.1016/j.bmcl.2018.04.004

8. Clausen, F., Kischkewitz, M., Bergander, K., Studer, A. (2019) Catalytic protodeboronation of pinacol boronic esters: formal anti-Markovnikov hydromethylation of alkenes, Chem Sci 10, 6210-6214. https://doi.org/10.1039/c9sc02067e

9. Liu, C., Li, X., Wu, Y. (2015) Base-promoted silver catalyzed protodeboronation of arylboronic acids and esters, RSC Adv 5 , 15354-15358. https://doi.org/10.1039/c4ra16323k

10. Yamamoto, Y., Takizawa, M., Yu, X.-Q., Miyaura, N. (2008) Cyclic triolborates: air- and water-stable ate complexes of organoboronic acids, Angew Chem Int Ed 47, 928-931. https:/ / doi.org/10.1002/ anie.200704162

11. Sakae, R. Hirano, K., Satoh, T., Miura, M. (2013) Formal anti-Markovnikov hydroamination of terminal aryl alkynes with pinacolborane and hydroxylamines via Zr/Cu sequential catalysis, Chem Lett 42, 1128-1130. https:// doi.org/ 10.1246/ cl.130485

12. Vantourout, J. C., Law, R. P., Isidro-Llobet, A., Atkinson, S. J., Watson, A. J. B. (2016) Chan-Evans-Lam amination of boronic acids pinacol (Bpin) esters: Overcoming the Aryl Amine Problem, J Org Chem 81, 3942-3950. bttps:// doi.org/10.1021/acs.joc.6b00466

13. Sueki, S., Kuninobu, Y. (2013) Copper-catalyzed $N$ - and $O$-alkylation of amines and phenols using alkylborane reagents, Org Lett 15, 1544-1547. https://doi.org/10.1021/ol400323z.

14. Feng, C., Loh, T.-P. (2014) Rhodium(III)-catalyzed cross-coupling of alkenylboronic acids and N-pivaloyloxylamides, Org Lett 16, 3444-3447. bttps:/ / doi.org/10.1021/ol501309e

15. Shade, R. E., Hyde, A. M., Olsen, J.-C., Merlic, C. A. (2010) Copper-promoted coupling of vinyl boronates and alcohols: a mild synthesis of allyl vinyl ethers, J Am Chem Soc 132, 1202-1203. https:// doi.org/10.1021/ja907982w

16. Marcum, J. S., McGarry, K. A., Ferber, C. J., Clark, T. B. (2016) Synthesis of biaryl ethers by the copper-catalyzed ChanEvans-Lam etherification from benzylic amine boronate esters, J Org Chem 81, 7963-7969. https://doi.org/10.1021/acs.joc.6b01254

17. Chan, D. G., Winternheimer, D. J., Merlic, C. A. Enol silyl ethers via copper(II)-catalyzed C-O bond formation, Org Lett 13, 2778-2781. https://doi.org/10.1021/ol2009297

18. Kabalka, G. W., Guchhait, S. K. (2003) Synthesis of (E)-and (Z)-alkenylphosphonates using vinylboronates, Org Lett 5, 729731. bttps:// doi.org/10.1021/ol027515a

19. Zhuang, R., Xu, J., Cai, Z., Tang, G., Fang, M., Zhao, Y. (2011) Copper-catalyzed C-P bond construction via direct coupling of phenylboronic acids with H-phosphonate diesters, Org Lett 13, 2110-2113. https:/ / doi.org/ 10.1021/ol200465z

20. Kanemoto, K., Yoshida, S., Hosoya, T. (2018) Modified conditions for copper-catalyzed ipso-thiolation of arylboronic acid esters with thiosulfonates, Chem Lett 47, 85-88. https://doi.org/10.1246/cl.170907

21. Xu, H.-J., Zhao, Y.-Q., Feng, T., Feng, Y.-S. (2012) Chan-Lam-type S-arylation of thiols with boronic acids at room temperature, J Org Chem 77, 2878-2884. https:// doi.org/10.1021/jo300100x

22. Scott, H. K., Aggarwal, V. K. (2011) Highly enantioselective synthesis of tertiary boronic esters and their stereospecific conversion to other functional groups and quaternary stereocentres, Chem Eur J 17, 13124-13132. https://doi.org/10.1002/chem.201102581

23. Brown, H. C. (1961) Hydroboration-a powerful synthetic tool, Tetrahedron 12, 117-138. https://doi.org/10.1016/00404020(61)80107-5

24. Woods, W. G., Strong, P. L., (1966) 4,4,6-Trimethyl-1,3,2-dioxaborinane. A stable dialkoxyborane, J Am Chem Soc 88, 46674671. bttps://doi.org/10.1021/ja00972a027

25. Irvine, G. J., Lesley, M. J. G., Marder, T. B., Norman, N. C., Rice, C. R., Robins, E. G., Roper, W. R., Whittell, G. R., Wright L. J., (1998) Transition metal-boryl compounds: synthesis, reactivity, and structure, Chem Rev 98, $2685-2722$. https:/ / doi.org/10.1021/CR9500085

26. Beletskaya, I., Pelter, A., (1997) Hydroborations catalyzed by transition metal complexes, Tetrahedron 53, 4957-5026. https:// doi.org/10.1016/S0040-4020(97)00001-X

27. Bauer, I., Knölker, H.-J. (2015) Iron catalysis in organic synthesis, Chem Rev 115, 3170-3387. bttps:/ / doi.org/10.1021/ cr500425u

28. Gorgas, N., Alves, L. G., Stö, B., Martins, A. M., Veiros, L. F., Kirchner, K. (2017) Stable, yet highly reactive nonclassical iron(II) polyhydride pincer complexes: Z-selective dimerization and hydroboration of terminal alkynes, J Am Chem Soc 139, 8130-8133. https:// doi.org/10.1021/jacs.7b05051

29. Mandal, S., Verma, P. K., Geetharani, K. (2018) Lewis acid catalysis: regioselective hydroboration of alkynes and alkenes promoted by scandium triflate, Chem Commun 54, 13690-13693. https:/ / doi.org/10.1039/C8CC08361D

30. Mamidala, R., Pandey, V. K., Rit, A. (2019) AgSbF 6 -catalyzed anti-Markovnikov hydroboration of terminal alkynes, Chem Commun 55, 989-992. https:// doi.org/10.1039/C8CC07499B

31. Jang, W. J., Kang, B.-N., Lee, J. H., Choi, Y. M., Kim, C.-H., Yun, J. (2019) NHC-copper-thiophene-2-caroxylate complex for the hydroboration of terminal alkynes, Org Biomol Chem 17, 5249-5252. https:// doi.org/10.1039/C9OB00839J

32. Wang, Y., Guan, R., Sivaguru, P., Cong, X., Bi, X. (2019) Silver-catalyzed anti-Markovnikov hydroboration of C-C multiple bonds, Org Lett 21, 4035-4038. https:/ / doi.org/10.1021/ acs.orglett.9b01217 
33. Hill, M. S., Liptrot, D. J., Weetman, C. (2016) Alkaline earths as main group reagents in molecular catalysis, Chem Soc Rev 45, 972-988. bttps:// doi.org/10.1039/C5CS00880H

34. Magre, M., Maity, B., Falconnet, A., Cavallo, L., Rueping, M. (2019) Magnesium-catalyzed hydroboration of terminal and internal alkynes, Angew Chem Int Ed 58, 7025-7029. https:/ / doi.org/10.1002/ anie.201902188

35. Nikonov, G. I. (2017) New tricks for an old dog: aluminum compounds as catalysts in reduction chemistry, ACS Catal 7 , 7257-7266. https:// doi.org/10.1021/ acscatal.7b02460

36. Bismuto, A., Cowley, M. J., Thomas, S. P. (2018) Aluminum-catalyzed hydroboration of alkenes, ACS Catal 8, $2001-2005$. https:// doi.org/10.1021/ acscatal.7b04279

37. Harinath, A., Banerjee, I., Bhattacharjee, J., Panda, T. K. (2019) Aluminum complex-catalyzed hydroboration of alkenes and alkynes, New J Chem 43, 10531-10536. https://doi.org/10.1039/c9nj01859j

38. Wu, Y., Shan, C., Ying, J., Su, J., Zhu, J., Liu, L. L., Zhao, Y. (2017) Catalytic hydroboration of aldehydes, ketones, alkynes and alkenes initiated by $\mathrm{NaOH}$, Green Chemistry 19, 4169-4175. https://doi.org/10.1039/C7GC01632H

39. Ma, D. H., Jaladi, A. K., Lee, J. H., Kim, T. S., Shin, W. K., Hwang, H., An, D. K. (2019) Catalytic hydroboration of aldehydes, ketones, and alkenes using potassium carbonate: a small key to big transformation ACS Omega 4, 15893-15903. https:/ / doi.org/10.1021/ acsomega.9b01877

40. Garrett, C. E., Fu, G. C. (1996) Hydroboration of olefins with catecholborane at room temperature in the presence of N,Ndimethylacetamide, Org Chem 61, 3224-3225. https:/ / doi.org/10.1021/JO960386P

41. Ho, H. E., Asao, N., Yamamoto, Y., Jin, T. (2014) Carboxylic acid-catalyzed highly efficient and selective hydroboration of alkynes with pinacolborane, Org Lett 16, 4670-4673. https:/ / doi.org/10.1021/ol502285s

42. Hoyt, C. B., Sarazen, M. L., Jones, C. W. (2019) Hydroboration of substituted alkynes using a solid polymeric carboxylic acid catalyst, J Catal 369, 493-500. https:/ / doi.org/10.1016/j.jcat.2018.11.021

43. Suseela, Y., Prasad, A. S., Periasamy, M., (1990) Catalytic effect of a BH $3: N, N$-diethylaniline complex in the formation of alkenyl catecholboranes from alk-1-ynes and catecholborane, J Chem Soc, Chem Commun 446-447. bttps:// doi.org/10.1039/C39900000446

44. Hoshi, M., Shirakawa, K., Arase, A. (2004) Preparation of (E)-1-Alkenylboronic Acid Pinacol Esters via Transfer of Alkenyl Group from Boron to Boron, Synthesis 11, 1814-1820. https:// doi.org/10.1055/s-2004-829165

45. Arase, A., Hoshi, M., Mijin, A., Nishi, K. (2006) Dialkylborane-catalyzed hydroboration of alkynes with 1,3,2benzodioxaborole in tetrahydrofurane, Synth Commun 25, 1957-1962. https:/ / doi.org/10.1080/00397919508015872

46. Anj, N. W., Buettner, C. S., Docherty, S., Bismuto, A., Carney, J. R., Docherty, J. H., Cowley, M. J., Thomas, S. P. (2018) Borane-Catalyzed Hydroboration of Alkynes and Alkenes, Synthesis 50, 803-808. https://doi.org/10.1055/s-0036-1591719

47. Yin, Q., Kemper, S., Klare, H. F. T., Oestreich, M. (2016) Boron Lewis acid-catalyzed hydroboration of alkenes with pinacolborane: $\mathrm{BAr} \mathrm{F}_{3}$ does what $\mathrm{B}\left(\mathrm{C}_{6} \mathrm{~F}_{5}\right)_{3}$ cannot do, Chem Eur J 22, 13840-13844. http:/ / dx.doi.org/10.1002/ chem.201603466

48. Carden, J. L., Gierlichs, L. J., Wass, D. F., Browne, D. L., Melen, R. L. (2019) Unlocking the catalytic potential of tris(3,4,5trifluorophenyl)borane with microwave irradiation, Chem Commun 55, 318-321. http:// dx.doi.org/ 10.1039/C8CC09459D

49. 9-BBN was used as a $0.5 \mathrm{M}$ solution in THF. The final reaction concentration was $2.5 \mathrm{M}$.

50. Hitosugi, S., Tanimoto, D., Nakanishi, W., Isobe, H. (2012) A facile chromatographic method for purification of pinacol boronic esters, Chem Lett 41, 972-973. https:/ / doi.org/10.1246/ cl.2012.972

51. Peng, A.-Y., Chen, B.-T., Chen, P.-J. (2013) An efficient synthesis of 2-(1-(E)-alkenyl)phenylphosphonates via Suzuki reaction of aryl nonaflates with (E)-1-alkenylboronates, J Fluorine Chem 151, 58-62. bttps://doi.org/10.1016/j.jfluchem.2013.03.015

52. Fairlamb, I. J. S., Marrison, L. R., Dickinson, J. M., Lu, F.-J., Schimdt, J.P. (2004) 2-Pyrones possessing antimicrobial and cytotoxic activities, Bioorgan Med Chem 12, 4285-4299. https:// doi.org/10.1016/j.bmc.2004.01.051

\section{ABOUT THE STUDENT AUTHORS}

Garett Ruesch graduated Summa Cum Laude from Southern Utah University in 2020 with an ACS-certified B.S. degree in chemistry with an emphasis in professional chemistry and minors in Spanish and mathematics. While at SUU, Garett was a twotime recipient of the Walter Maxwell Gibson Research Fellowship, and was awarded the 2019 ACS Undergraduate Award in Physical Chemistry and 2020 ACS Division of Organic Chemistry Outstanding, Senior Chemistry Student at SUU. He currently pursues a Ph.D. degree in chemistry at the University of California, Los Angeles and ultimately a professorship.

Sydney Rowley plans to graduate from Southern Utah University in the spring of 2021 with an ACS-certified B.S. degree in chemistry with an emphasis in professional chemistry and a minor in mathematics. Sydney has received the Walter Maxwell Gibson Research Fellowship and the L. S. and Aline W. Skaggs Research Grant. After graduation, she plans on pursuing a Ph.D. degree in chemistry and a career in the pharmaceutical industry.

Marcus Mifflin graduated Summa Cum Laude from Southern Utah University in 2019 with an ACS-certified B.S. degree in chemistry with an emphasis in professional chemistry and minors in mathematics and physics. While at SUU, Marcus was the 
recipient of the Walter Maxwell Gibson Research Fellowship, and he received the Outstanding Research Award in the Department of Physical Science. He currently pursues a Ph.D. degree in chemistry at the University of Utah and ultimately a professorship.

\section{PRESS SUMMARY}

Boron containing organic compounds are useful reagents in the synthesis of important carbon-containing medicines, materials, and fine chemicals. The alkenylboronic acid pinacol esters formed from hydroboration reaction of alkynes with pinacolborane are stable, easy to handle, and useful in many synthetic transformations. However, pinacolborane lacks the reactivity necessary to undergo facile hydroboration reaction with terminal aromatic alkynes. It was discovered that 9-borobicyclo[3.3.1]nonane (9-BBN) can be used to catalyze the hydroboration reaction of terminal aromatic alkynes with pinacolborane. The parameters of the experimental procedure were evaluated and an optimal set of reaction conditions were found. This work provides synthetic chemists with a method to prepare these important compounds. 